\title{
Epidermal growth factor receptor regulates fibrinolytic pathway elements in cervical cancer: functional and prognostic implications
}

\author{
F.G. Gomes ${ }^{1 \oplus}$, V.H. Almeida ${ }^{1 \oplus}$, K. Martins-Cardoso ${ }^{1 \oplus}$, M.M.D.C. Martins-Dinis ${ }^{1,2 \odot}$ \\ A.M.R. Rondon ${ }^{1 \oplus}$, A.C. de Melo ${ }^{3 \oplus}$, T.M. Tilli ${ }^{4 \oplus}$, and R.Q. Monteiro ${ }^{1 \oplus \infty}$ \\ ${ }^{1}$ Instituto de Bioquímica Médica Leopoldo de Meis, Universidade Federal do Rio de Janeiro, Rio de Janeiro, RJ, Brasil \\ ${ }^{2}$ Instituto Nacional de Ciência e Tecnologia de Biologia Estrutural e Bioimagem, Universidade Federal do Rio de Janeiro, \\ Rio de Janeiro, RJ, Brasil \\ ${ }^{3}$ Clinical Research Division, Instituto Nacional de Câncer, Rio de Janeiro, RJ, Brasil \\ ${ }^{4}$ Plataforma de Oncologia Translacional, Centro de Desenvolvimento Tecnológico em Saúde, Fundação Oswaldo Cruz, \\ Rio de Janeiro, RJ, Brasil
}

\begin{abstract}
Epidermal growth factor receptor (EGFR) signaling and components of the fibrinolytic system, including urokinase-type plasminogen activator (UPA) and thrombomodulin (TM), have been implicated in tumor progression. In the present study, we employed cBioPortal platform (http://www.cbioportal.org/), cancer cell lines, and an in vivo model of immunocompromised mice to evaluate a possible cooperation between EGFR signaling, UPA, and TM expression/function in the context of cervical cancer. cBioPortal analysis revealed that EGFR, UPA, and TM are positively correlated in tumor samples of cervical cancer patients, showing a negative prognostic impact. Aggressive human cervical cancer cells (CASKI) presented higher gene expression levels of EGFR, UPA, and TM compared to its less aggressive counterpart (C-33A cells). EGFR induces uPA expression in CASKI cells through both PI3K-Akt and MEK1/2-ERK1/2 downstream effectors, whereas TM expression induced by EGFR was dependent on PI3K/Akt signaling alone. uPA induced cell-morphology modifications and cell migration in an EGFR-dependent and -independent manner, respectively. Finally, treatment with cetuximab reduced in vivo CASKI xenografted-tumor growth in nude mice, and decreased intratumoral uPA expression, while TM expression was unaltered. In conclusion, we showed that EGFR signaling regulated expression of the fibrinolytic system component uPA in both in vitro and in vivo settings, while uPA also participated in cell-morphology modifications and migration in a human cervical cancer model.
\end{abstract}

Key words: Cervical cancer; Epidermal growth factor receptor; Urokinase-type plasminogen activator; Thrombomodulin; Fibrinolytic system

\section{Introduction}

Cervical cancer is the fourth most incident type of cancer among women, with 570,000 new estimated cases in 2018 (1), a vast majority of which occurring in developing countries. Cervical cancer is the third most common type of malignancy among Brazilian women, with a high mortality rate (2). The major risk factor for cervical cancer is human papillomavirus (HPV) infection (3).

The epidermal growth factor receptor (EGFR) has been associated with cervical cancer progression $(4,5)$. EGFR is well described concerning its involvement in several processes such as proliferation and resistance to chemotherapy. Furthermore, EGFR expression has been correlated with poor survival among cervical cancer patients (6). HPV infection was shown to increase the amount of EGF receptors exposed on the cell membrane (by inhibiting EGFR degradation) (7) and enhance the expression of intracellular signal transducers commonly associated with EGFR signaling, such as phosphatidylinositol-3 kinase (PI3K) and extracellular signal-regulated kinase (ERK) (8). Different clinical trials have been performed employing anti-EGFR therapy for cervical cancer patients, showing ambiguous results: either with no beneficial outcomes (9), treatment-associated side effects (10), or an approximate $10 \%$ increase in overall survival (11).

A different group of receptors and secreted proteins that have been increasingly shown to participate in cancer invasion and metastasis is the fibrinolytic system. 
The fibrinolytic system is classically associated with the degradation of fibrin clots in the blood. However, the study performed by Malone and coworkers showed that cancer tissues from metastatic foci had increased fibrinolytic activity compared to primary non-metastatic tumor samples (12). The generation of plasmin, a key effector in the fibrinolytic system within the cancer microenvironment, has been demonstrated to be involved in extracellular matrix degradation, pro-ligand and pro-metalloprotease cleavage, and tumor cell invasion in different models (13-15). Plasmin is generated by cleavage of the circulating inactive plasminogen by plasminogen activators, such as urokinase-type plasminogen activator (UPA), which is the most relevant plasminogen activator within solid tissues. Furthermore, plasminogen can bind to different receptors on the cell surface, such as thrombomodulin (TM), annexin A2 (ANXA2), and S100 calcium-binding protein A10 (S100A10) $(16,17)$. High expressions of uPA and uPA receptor (UPAR) have already been shown to correlate with cancer metastasis and worse patient prognosis (18).

EGFR signaling has been directly linked with components of the fibrinolytic system, for example, in breast cancer and glioblastoma. Jo et al. (19) showed that EGFR signaling was inhibited in breast cancer cells by silencing or inhibiting uPAR. Furthermore, in glioblastoma, EGFR was shown to induce uPA expression by proto-oncogene tyrosine-protein kinase Src (c-Src) and ERK signaling (20). A possible compensatory mechanism may also take place in glioblastoma where there is an increased expression of both UPA and UPAR in response to EGFR inhibition, favoring resistance to EGFR-targeted therapy $(21,22)$.

It remains unanswered, however, if EGFR signaling is related somehow to components of the fibrinolytic system in cervical cancer. In the present work, we observed a positive expression correlation between EGFR and several fibrinolytic system elements, including UPA and TM on human cervical tumor samples, with prognostic significance. We also observed that EGFR signaling positively regulated expression of both $U P A$ and TM in an aggressive cervical cancer cell line, and that uPA expression led to cell morphology alterations and increased migration. Finally, in vivo, we observed that treatment with an anti-EGFR antibody, cetuximab injected subcutaneously, reduced tumor growth, a process that was accompanied by a decreased intra-tumoral expression of uPA.

\section{Material and Methods}

\section{Expression-correlation analysis}

Transcriptome data from 302 patients were collected from the "TCGA, Firehouse Legacy" cohort on the platform cBioPortal (http://www.cbioportal.org/) $(23,24)$ between May 22, 2020 and May 23, 2020. This cohort had 304 patients (as of May 23, 2020) two of which had two samples taken (totaling 306 samples from 304 patients). These two patients were excluded from the analysis, therefore the total number of samples/patients shown in the present work is 302. mRNA expression (RNA Seq V2 RSEM) in FPKM (frames per kilobase per million) data was downloaded, plotted using Graphpad Prism ${ }^{\mathrm{TM}}$ (USA), and analyzed by non-parametric Spearman correlation.

\section{Overall survival analysis}

From the cBioPortal platform, we established a cut-off of 1.5 standard deviations above the median of expression to separate groups of "overexpression" and "cases without alteration" of the cohort "TCGA, Firehouse Legacy", from the 302 patients. After the establishment of the gene expression cut-off, we analyzed overall survival at the "survival" window on cBioPortal, extracted the data, and assembled the graphs with Graphpad ${ }^{\mathrm{TM}}$. Mantel-Cox test was used for statistical analysis.

\section{Cell lines}

Human cervical cancer cells CASKI (more aggressive) and C-33A (less aggressive) were cultivated in RPMI medium supplemented with $10 \%$ fetal bovine serum (FBS), and maintained in $37^{\circ} \mathrm{C}, 5 \% \mathrm{CO}_{2}$. CASKI cell line was originated from an intestinal metastasis of an epidermoid cervical carcinoma and was infected with multiple copies of HPV-16 (ATCC, CRL-1550 ${ }^{\mathrm{TM}}$ ). C-33A cells originated from a primary epidermoid cervical carcinoma, uninfected by HPV (ATCC, HTB-31 ${ }^{\mathrm{TM}}$ ).

\section{Real-time PCR}

Briefly, C-33A or CASKI were seeded $\left(4 \times 10^{5}\right.$ cells/ well) onto 6-well plates, in RPMI medium supplemented with $10 \%$ FBS. The next day, the wells were washed with phosphate-buffered saline (PBS) and cells were starved (FBS-free medium) for $16 \mathrm{~h}$. After starving, cells were treated with anti-EGFR antibody (cetuximab, Merck, Germany, $100 \mu \mathrm{g} / \mathrm{mL}$ ), PI3K inhibitor (LY294002, SigmaAldrich, USA, $25 \mu \mathrm{M}$ ), or MEK inhibitor (PD98059, SigmaAldrich, $50 \mu \mathrm{M})$, for $1 \mathrm{~h}$. Then, cells were treated with EGF (50 ng/mL) for $1.5 \mathrm{~h}$ or $3 \mathrm{~h}, 37^{\circ} \mathrm{C}, 5 \% \mathrm{CO}_{2}$. The wells were washed with PBS and 0.5-1 mL Trizol (Sigma-Aldrich) was added to each well. The extracts were transferred into microcentrifuge tubes and stored at $-20^{\circ} \mathrm{C}$, for posterior RNA isolation. From each sample, $1 \mu \mathrm{g}$ of total RNA was reverse transcribed to cDNA. Next, quantitative PCR was performed on cDNA aliquots.

For TM real-time PCR, $5 \mu \mathrm{L}$ master mix (Thermo Fisher Scientific, USA), $0.5 \mu \mathrm{L}$ TaqMan probe for human TM (Hs00264920_s1) or human GAPDH (reference gene, 4326317E), $2 \mu \mathrm{L}$ injection water, and $2.5 \mu \mathrm{L}$ diluted cDNA $(1: 20 \mathrm{v} / \mathrm{v})$ were added, totaling $10 \mu \mathrm{L}$ per well of a $96-$ well PCR plate. Quantitative PCR was performed with a StepOnePlus ${ }^{\mathrm{TM}}$ real-time PCR system (Thermo Fisher Scientific). The cycling conditions were: $95^{\circ} \mathrm{C}(20 \mathrm{~s})$, followed by 50 cycles of $95^{\circ} \mathrm{C}(1 \mathrm{~s})$ and $60^{\circ} \mathrm{C}(20 \mathrm{~s})$.

For uPA real-time PCR, 7.5 $\mu \mathrm{L}$ SYBR green mix, $0.6 \mu \mathrm{L}$ forward primer $(10 \mu \mathrm{M}), 0.6 \mu \mathrm{L}$ reverse primer 
$(10 \mu \mathrm{M})$ (both primers purchased from Thermo Fisher Scientific), $4.8 \mu \mathrm{L}$ injection water, and $1.5 \mu \mathrm{L}$ cDNA (diluted 1:20 v/v) were added, totaling $15 \mu \mathrm{L}$ per well of a 96-well PCR plate. The cycling conditions were: $95^{\circ} \mathrm{C}$ (10 min), followed by 45 cycles of $95^{\circ} \mathrm{C}(15 \mathrm{~s})$ and $60^{\circ} \mathrm{C}$ (1 $\mathrm{min})$. Finally, the melting curve was $95^{\circ} \mathrm{C}(15 \mathrm{~s})$, $60^{\circ} \mathrm{C}(1 \mathrm{~min})$, and $95^{\circ} \mathrm{C}(15 \mathrm{~s})$. In this case, $18 \mathrm{~S}$ was used as a reference gene (25) (Table 1$)$. The $(1+\text { efficiency })^{-\Delta \Delta C T}$ method was used to analyze the fold increase.

\section{Plasmin enzymatic activity assay}

CASKI or C-33A cells were seeded $\left(3 \times 10^{4} /\right.$ well) onto 96-well plates in RPMI medium supplemented with $10 \%$ FBS. When necessary, $100 \mu \mathrm{g} / \mathrm{mL}$ cetuximab was added to the wells after seeding and incubated for $30 \mathrm{~min}, 37^{\circ} \mathrm{C}$, $5 \% \mathrm{CO}_{2}$. Then, EGF was added to the wells of interest at 10,50 , or $100 \mathrm{ng} / \mathrm{mL}$ and the plates were incubated for $18 \mathrm{~h}$ at $37^{\circ} \mathrm{C}, 5 \% \mathrm{CO}_{2}$. The wells were washed twice with FBS/phenol red-free medium and UPA inhibitor (BC-11 hydrobromide, Abcam, USA) was added at a final concentration of $50 \mu \mathrm{M}$ for approximately $15 \mathrm{~min}$ at room temperature. After BC-11 incubation, lys-plasminogen was added at $0.5 \mu \mathrm{M}$, and $250 \mu \mathrm{M}$ of plasmin-chromogenic substrate S2251 (Diapharma, USA) was immediately pipetted to the wells. Plates were analyzed on a Spectramax 190 plate reader (Molecular Devices, USA) for $5 \mathrm{~h}$, at $37^{\circ} \mathrm{C}$, during which $405 \mathrm{~nm}$ reads were performed at 4 min intervals. All experiments were performed in duplicate.

\section{Flow cytometry}

Flow cytometry assays were performed using an antiTM antibody conjugated with the APC (allophycocyanin) fluorophore, which has peak excitation at $645 \mathrm{~nm}$ and emission at $660 \mathrm{~nm}$. Briefly, $5 \times 10^{5}$ cells were incubated with $2.5 \mu \mathrm{L}$ anti-TM antibody in $100 \mu \mathrm{L}$ final volume, $12.5 \mu \mathrm{g} / \mathrm{mL}$ final concentration (BioLegend, clone M80, USA), for $30 \mathrm{~min}$, on ice. The cells were then washed with PBS and resuspended on $400 \mu \mathrm{L}$ of FACs buffer (PBS + $5 \%$ FBS). Basal TM expression of C-33A and CASKI cells was evaluated on a FACSVerse ${ }^{\mathrm{TM}}$ machine (BD Biosciences, USA). TM-protein expression was also evaluated after stimuli with $50 \mathrm{ng} / \mathrm{mL}$ EGF + /- cetuximab, for $6 \mathrm{~h}$. The experiment was performed on an Accuri ${ }^{\mathrm{TM}}$ (BD Biosciences) flow cytometer, evaluating the percentage of positive events and mean fluorescence intensity (MFI).

\section{Cell morphology and migration}

CASKI cells $\left(5 \times 10^{5} /\right.$ well $)$ were seeded onto 6 -well plates. After $24 \mathrm{~h}$, cells were starved in FBS-free media for $10 \mathrm{~h}$ and treated with or without $0.5 \mu \mathrm{M}$ glu-plasminogen, $100 \mu \mathrm{g} / \mathrm{mL}$ cetuximab, and/or $50 \mu \mathrm{M}$ BC-11 for approximately $16 \mathrm{~h}$ at $37^{\circ} \mathrm{C}, 5 \% \mathrm{CO}_{2}$. Plates were photographed with a Qimaging camera (Q35443, CE, Canada), at 10× magnification. Immediately after the photographs, cells were harvested for the Boyden chamber migration assay, which was performed using $8-\mu \mathrm{m}$ pore polycarbonate membranes (Costar, USA). The lower compartments were

Table 1. Sequence and product size for the primers used on SYBR green real-time PCR protocol.

\begin{tabular}{llc}
\hline Gene name & \multicolumn{1}{c}{ Primers } & \multicolumn{1}{c}{ Product size } \\
\hline uPA & F: GTCACCTACGTGTGTGGAGG & 147 base pairs \\
& R: CTTCATCTCCCCTTGCGTGT & \\
$18 S$ & F: AACCCGTTGAACCCCATT & 149 base pairs (ref. 25) \\
& R: CCATCCAATCGGTAGTAGCG & \\
\hline
\end{tabular}

A

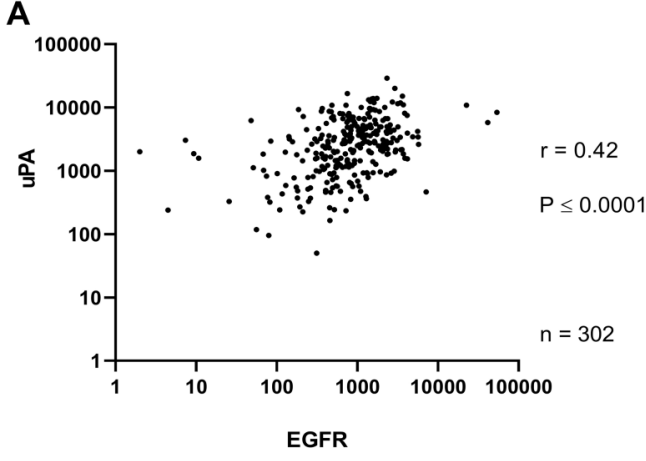

B

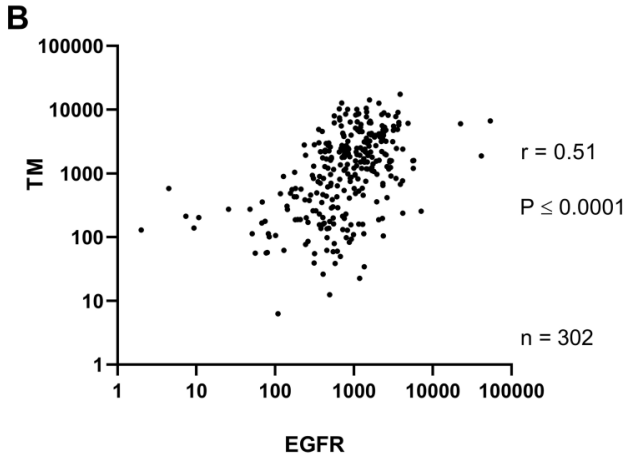

Figure 1. Epidermal growth factor receptor (EGFR), urokinase-type plasminogen activator (UPA), and thrombomodulin (TM) expressions have a positive correlation in samples from human cervical tumors. Data are reported as FPKM (frames per kilobase per million). Spearman correlation test was used for statistical analysis. 


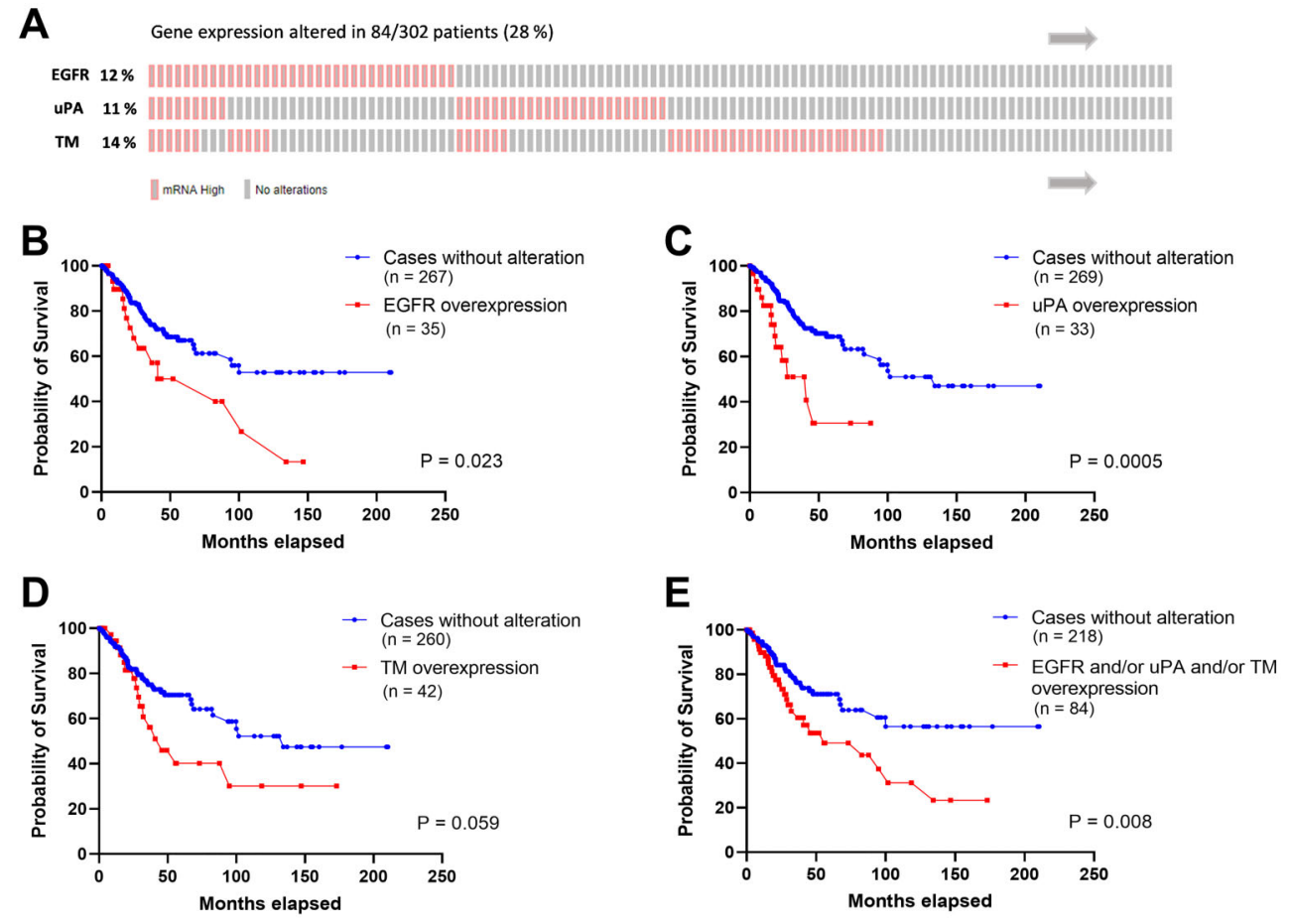

Figure 2. Overall survival analysis of cervical cancer patients concerning epidermal growth factor receptor (EGFR), urokinase-type plasminogen activator (UPA), and thrombomodulin (TM) tumor overexpression. A, Map of the alterations in the EGFR, TM, and uPA gene expression in tumor samples of 302 cervical cancer patients. Patients who exhibited overexpression of these genes in the tumor are indicated in red. This map was generated through cBioPortal, which is based on the clinical and molecular information provided by TCGA. Overall survival analysis of cervical cancer patients with gene expression of 1.5 standard deviations above the median for EGFR (B), uPA (C), TM (D), or any of the three genes, in an isolated or concomitant manner (E). Survival curve comparison was done through the Log-rank (Mantel-Cox) statistical test.

filled with RPMI media containing $5 \%$ FBS and $3 \times 10^{4}$ treated cells were seeded in $50 \mu \mathrm{L}$ serum-free media to the upper chambers. After $20 \mathrm{~h}$ of incubation, at $37^{\circ} \mathrm{C}$ with $5 \% \mathrm{CO}_{2}$, the non-migrated cells in the upper chambers were removed and the membranes were fixed and stained using the fast Panoptic staining kit (Laborclin, Brazil). Ten image fields were evaluated for each condition. The mean number of cells per field was calculated for each condition (of each experiment) and plotted.

\section{In vivo assays}

For in vivo assays, $1 \times 10^{7}$ CASKI cells were subcutaneously injected into both flanks of immunocompromised Balb/c nude female mice. One week later, when tumors became palpable, the size of tumors was calculated using the following formula: $V=D \times d^{2} / 2$, where $\mathrm{V}$ : tumor volume $\left(\mathrm{mm}^{3}\right)$; $\mathrm{D}$ : larger tumor mass diameter $(\mathrm{mm})$; $\mathrm{d}$ : smaller tumor diameter $(\mathrm{mm})$.

The measurements were made using a caliper. Day 0 was defined as the day when the cell injections were made, and then tumors were measured on days $7,9,12$, 14, and 15. Injected animals were separated into two groups: 1) Control group: treated intraperitoneally with $200 \mu \mathrm{L}$ PBS (4 animals); and 2) Intervention group: treated intraperitoneally with $200 \mu \mathrm{L}$ cetuximab $(1 \mathrm{mg} / \mathrm{animal}$, 3 animals). Both tumors in each animal were analyzed as an independent experimental unit. Treatments were performed on the same day of size measurements, except for day 15 . On day 15, the animals were anesthetized with ketamine/xylazine and euthanized by cervical displacement. Immediately after euthanasia, tumors were excised using scissors and scalpel and weighed on a precision scale. Finally, tumors were cut into smaller pieces with a scissor, inserted into $1.5 \mathrm{~mL}$ Eppendorf tubes containing Trizol, and stored at $-20^{\circ} \mathrm{C}$. Samples were then macerated using a Turrax homogenizer (Daigger Scientific, USA), which was washed with DEPC water, Trizol, $75 \%$ ethanol, and DEPC water, in this order, between samples. Samples were then further processed for real-time PCR. The use of animals in this work was approved by the Commission of Ethics in Animal Use of the Federal University of Rio de Janeiro, registered at the National Control Council of Animal Experimentation under the process number 01200.001568/2013-87, protocol 102/16. 

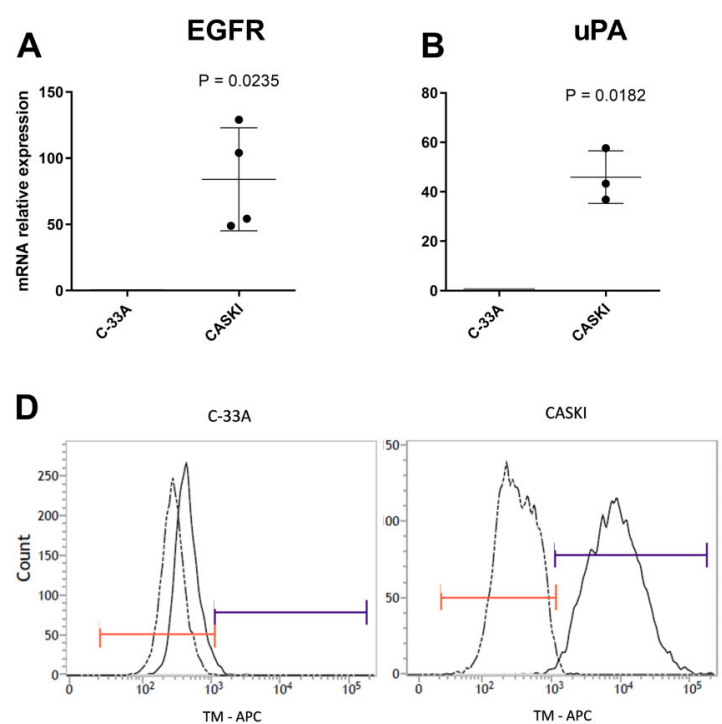
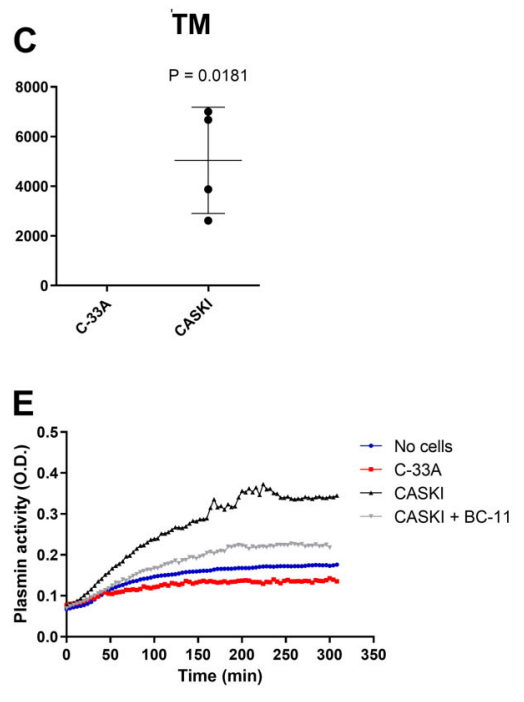

Figure 3. CASKI cells express higher levels of epidermal growth factor receptor (EGFR), urokinase-type plasminogen activator (UPA), and thrombomodulin (TM) compared to C-33A cells (A-C). Data are reported as means \pm SD of 3-4 independent experiments (unpaired $t$-test). D, Representative histograms of the flow cytometry for TM of C-33A and CASKI cells, analyzing the percentage of positive events. E, Representative graph of the plasmin enzymatic activity assay of C-33A and CASKI cells $(+/-$ UPA inhibitor, BC-11, $50 \mu \mathrm{M})$ followed by $0.5 \mu \mathrm{M}$ lys-plasminogen and $250 \mu \mathrm{M}$ chromogenic substrate S2251, analyzed over $5 \mathrm{~h}$ with $4 \mathrm{~min}$ between each read at $405 \mathrm{~nm}$.

\section{Data analysis and presentation}

When comparing two groups, one-sample t-test (when one of the group's data had been normalized to "1") or two-sample unpaired two-tailed $t$-test was employed. For multiple comparisons, one-way ANOVA with Tukey's posttest was used. All statistical analyses were done with Graphpad Prism ${ }^{\mathrm{TM}}$. When applicable, data are reported as means $\pm S D$ (with the exception of Figure $6 \mathrm{~A}$, which reports means $\pm S E$ ). Experimental units for in vitro assays were considered to be the mean result of each experiment, performed on different cell-culture passages.

\section{Results}

EGFR, UPA, and TM expressions were positively correlated in samples from human cervical cancer tumors, which correlated with poor overall survival

A positive correlation between EGFR $x$ uPA expressions ( $r=0.42, P<0.0001$, Figure $1 A)$ and EGFR $\times$ TM expressions ( $r=0.51, P<0.0001$, Figure $1 B$ ) was observed in cervical cancer samples. In the criteria established in the current study, the mRNA upregulation of EGFR, UPA, and $\mathrm{TM}$ was found in 12,11, and $14 \%$ of the cases, respectively (Figure 2A). Furthermore, cervical cancer patients with increased expression of EGFR $(P=0.023$, Figure $2 B)$, uPA ( $P=0.0005$, Figure $2 C)$, or TM $(P=0.059$, Figure 2D) had decreased overall survival compared to the patients with normal levels. The effect of the upregulation in one, two, or all three genes in this group of patients $(n=84)$ was also significantly associated with poor overall survival ( $P=0.008$, Figure $2 E)$. A positive correlation between EGFR expression and other components of the fibrinolytic system (Table S1) was also observed, although the increased expression of each gene showed no correlation with alterations of overall survival of the cervical cancer patients (Supplementary Figure S1).

\section{CASKI cells expressed higher levels of EGFR, UPA, and TM compared to C-33A cells}

The more aggressive CASKI cells expressed higher mRNA levels of the EGFR, uPA, and TM (Figure 3A-C) genes compared to $\mathrm{C}-33 \mathrm{~A}$. On a protein level, $\mathrm{C}$-33A cells were negative for TM, as observed by flow cytometry, whereas CASKI cells were mostly positive (Figure 3D). C-33A cells also did not generate active plasmin from added plasminogen (reaction catalyzed by cell-produced plasminogen activators, such as UPA) while, in contrast, CASKI cells had an uPA-dependent generation of active plasmin (Figure 3E). Previously published data from our group shows that CASKI cells have higher protein levels of EGFR compared to C-33A cells (26).

\section{EGFR signaling upregulated UPA and TM expression in CASKI cells}

On a protein level, the addition of the anti-EGFR monoclonal antibody cetuximab reduced basal plasmin generation, as well as reverted the EGF-mediated increase of plasmin activity (Figure 4A) in CASKI cells. EGF addition to C-33A cells did not alter uPA expression or plasmin generation (Supplementary Figure S2). 

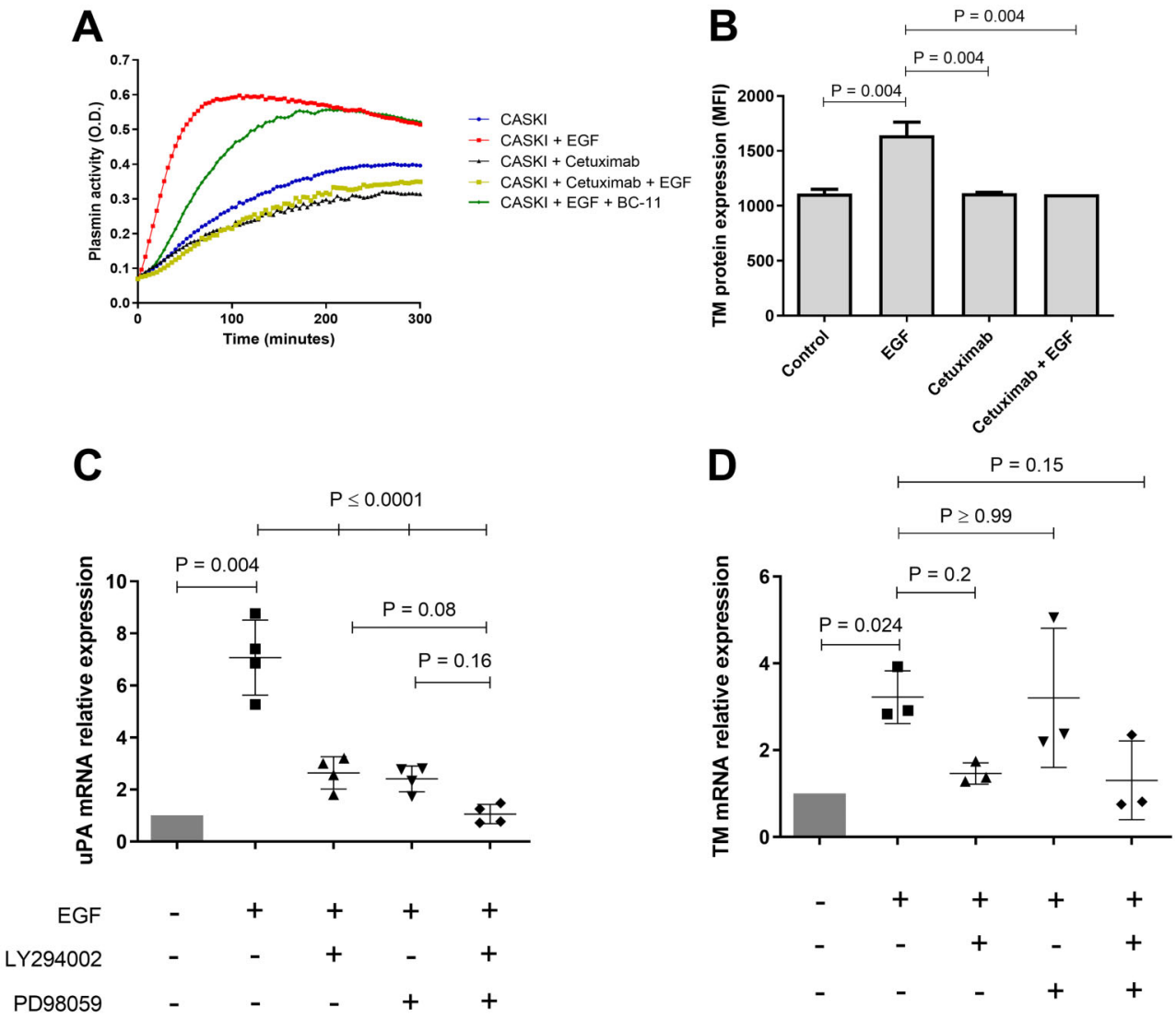

Figure 4. Epidermal growth factor receptor (EGFR) signaling upregulates urokinase-type plasminogen activator (UPA) and thrombomodulin (TM) expression in CASKI cells. A, Representative graph of the plasmin enzymatic activity assay performed with CASKI cells treated overnight with epidermal growth factor (EGF) alone, cetuximab alone, EGF 30 min after cetuximab treatment, or EGF overnight plus BC-11 15 min before starting measurements. B, Flow cytometry staining for TM in CASKI cells treated with EGF, cetuximab, or the combination of both. Data are reported as mean fluorescence intensity \pm SD. One-way ANOVA with Tukey's post-test was used for statistical analysis. Real-time PCR for UPA (C) or TM (D) in CASKI cells treated with EGF + /- LY294002, + /- PD98059. A one-sample $t$-test was performed for comparisons to the normalization control "CASKI", and one-way ANOVA with Tukey's post-test was performed for the remaining comparisons. In all cases, LY294002 and PD98059 were added to the cells $1 \mathrm{~h}$ before EGF addition, which was then done for $15 \mathrm{~min}$ (western blot) or $1.5 \mathrm{~h}$ (real-time PCR). Final concentrations were: $50 \mathrm{ng} / \mathrm{mL}$ EGF, $25 \mu \mathrm{M} \mathrm{LY} 294002$, and $50 \mu \mathrm{M}$ PD98059.

EGF-induced plasmin generation in CASKI cells was promoted by uPA (Figure 4A). TM protein expression increased with EGF addition to CASKI cells, and such effect was reverted by cetuximab (Figure 4B, Supplementary Figure S3).

In order to evaluate whether EGFR signaling had a direct impact on UPA and TM expression, CASKI cells were incubated with EGF with or without inhibitors of the downstream EGFR-signaling branches PI3K-Akt (LY294 002) and MEK1/2-ERK1/2 (PD98059) (Figure 4C and D). EGF-induced uPA expression was significantly diminished in CASKI cells by both inhibitors (Figure 4C), whereas EGF-induced TM expression was significantly diminished by PI3K inhibition (Figure 4D).

\section{uPA participated in morphology-altering and migration phenomena in CASKI cells}

To assess the possible functional impact that EGFRdependent plasmin generation may have on CASKI cells, we evaluated the cell morphology under different treatments (Figure 5A-E). Upon plasminogen addition, cells changed their morphology into a highly connected state, assembling into "branched" structures composed of overlapping cells, as opposed to the control-monolayer cell disposition (Figure $5 A$ and $B$ ). Both UPA and EGFR inhibition, in an isolated manner, hampered this plasminogen-induced cell-morphology alteration (Figure $5 \mathrm{C}$ and $\mathrm{D}$ ) and the combination of both inhibitors seemed to reverse this effect to a state that mostly resembled the control group (Figure $5 \mathrm{E}$ ). 


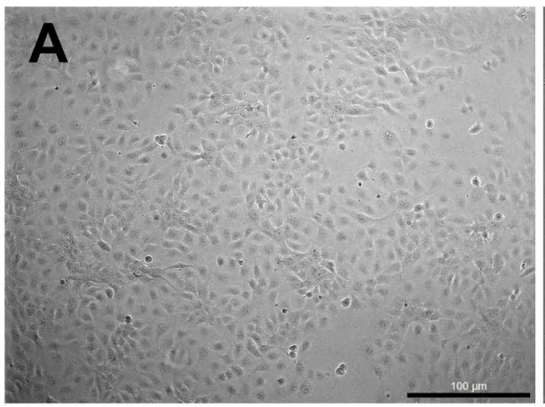

Control

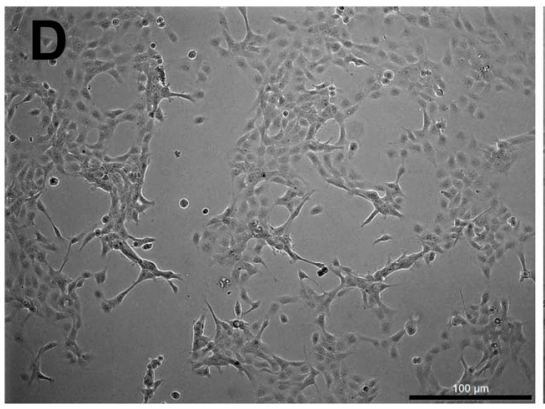

+ Cetuximab

+ Plasminogen

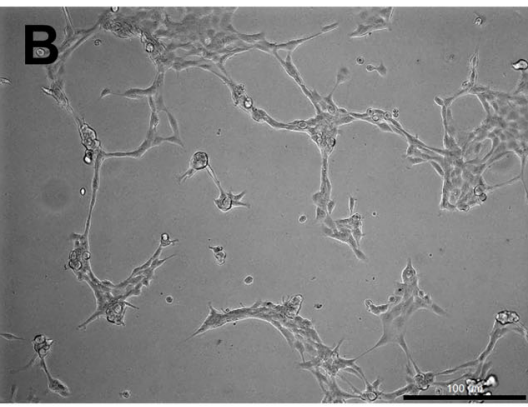

+ Plasminogen

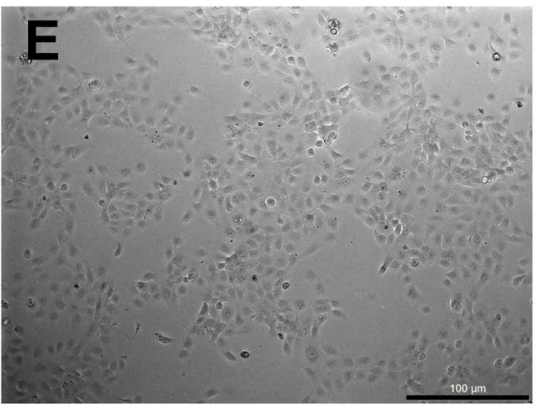

$+\mathrm{BC}-11$

+ Cetuximab

+ Plasminogen

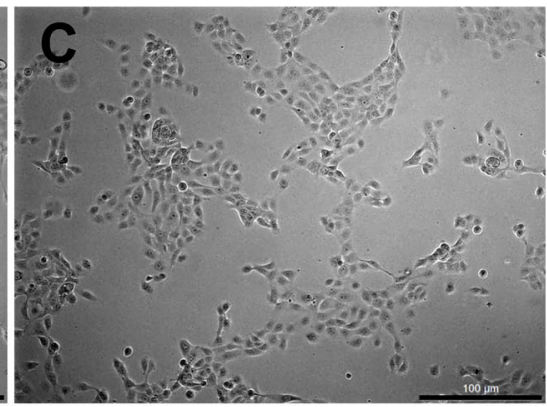

$+\mathrm{BC}-11$

+ Plasminogen
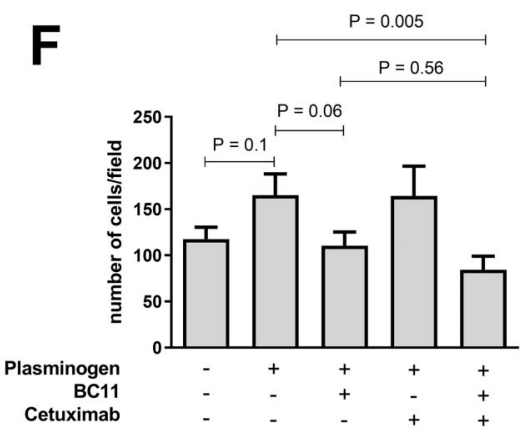

Figure 5. Epidermal growth factor receptor (EGFR)/urokinase-type plasminogen activator (UPA) participated in morphology-altering and migration phenomena in CASKI cells. A-E, Bright field light microscopy pictures (100× magnification, scale bar $100 \mu \mathrm{m})$ of CASKI cells treated for $16 \mathrm{~h}$ with plasminogen $+/-$ UPA inhibitor (BC-11) or $+/-$ anti-EGFR monoclonal antibody (cetuximab). $\mathrm{F}$, Cell migration experiment in the Boyden chamber was performed on the cells treated the same as in the microscopy images. Final treatment concentrations: $0.5 \mu \mathrm{M}$ glu-plasminogen, $50 \mu \mathrm{M} \mathrm{BC}-11$, and $100 \mu \mathrm{g} / \mathrm{mL}$ cetuximab. Data are reported as means \pm SD of three independent experiments. One-way ANOVA with Tukey's post-test was used for statistical analysis.

Cell migration experiments were performed immediately after cell-morphology images were taken and, although plasminogen addition led to a trend of increased cell migration on a Boyden chamber model, EGFR or UPA inhibition alone did not decrease plasminogen-induced cell migration, whereas the combination of both inhibitors significantly hampered this process (Figure $5 \mathrm{~F}$ ).

\section{In vivo treatment with cetuximab decreased tumor growth/weight and intra-tumoral uPA expression}

Cetuximab treatment reduced in vivo tumor growth and weight (Figure $6 \mathrm{~A}$ and $\mathrm{B}$ ) and led to a trend of uPA expression reduction within the tumor tissue (Figure $6 \mathrm{C})$, whereas TM expression was unaffected by in vivo cetuximab treatment (Figure 6D).

\section{Discussion}

Cervical cancer is a type of malignancy that, unfortunately, still imposes a great burden on women living in low and middle income countries. Although the standard treatment consisting on surgical resection for initial disease or chemotherapy in combination with radiotherapy for locally advanced disease is of fundamental importance, there is still a great need for: 1) new therapeutic targets and 2) biomarkers for screening patients that could benefit more from certain targeted therapies. EGFR has been considered to be a receptor involved in cervical cancer progression $(4,5)$, however, clinical trials are still not conclusive as to whether blocking EGFR is effective enough for justifying its use in the clinical setting (9-11). Furthermore, it has been described that, in other types of cancer in which anti-EGFR treatment is Food and Drug Administration-approved, it is quite common for patients to develop resistance mechanisms towards EGFR-targeted therapy (27).

In the present work, EGFR, uPA, and TM expression had a positive correlation on human cervical tumor samples, and the high expression of these genes was associated with worse patient overall survival. 

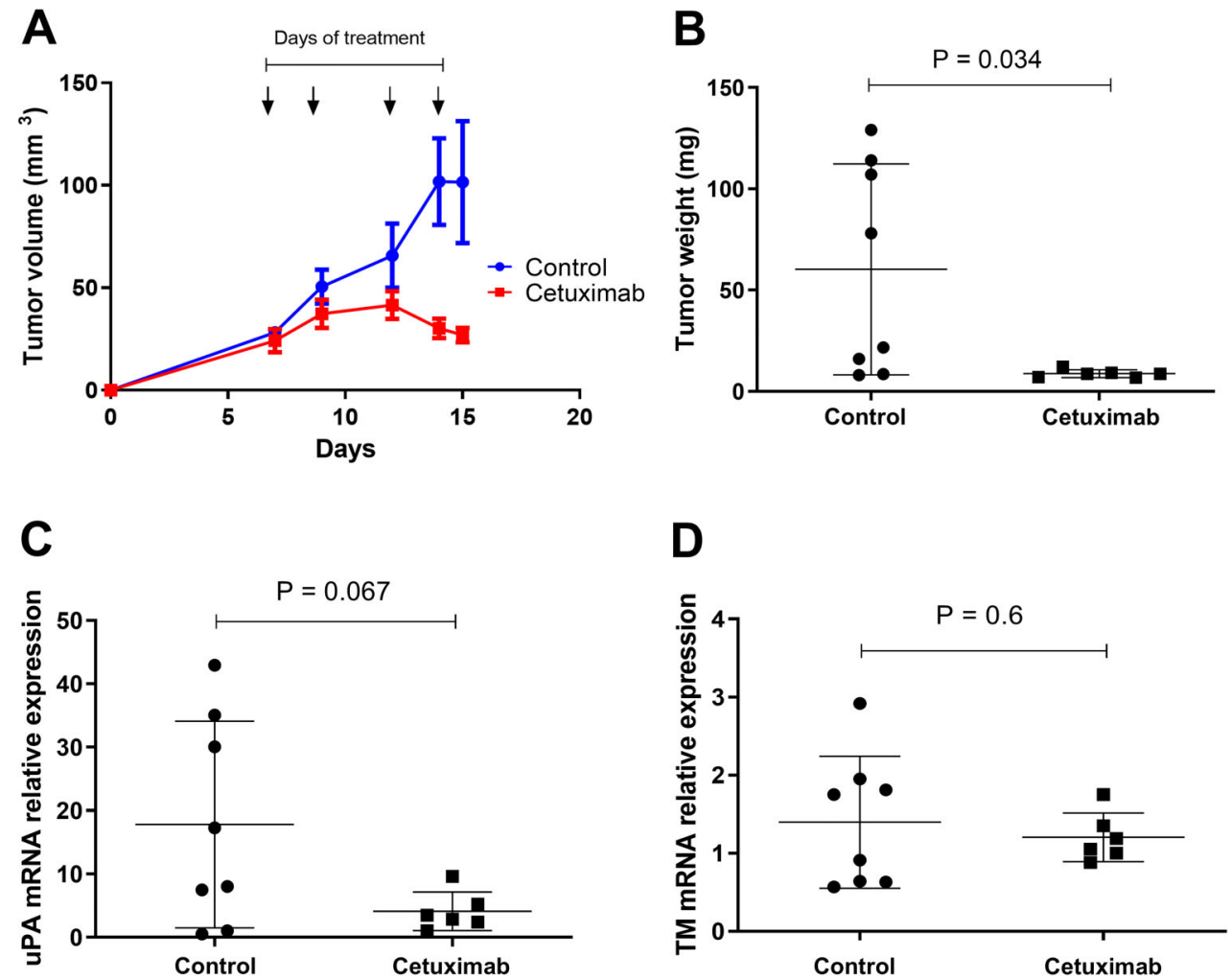

Figure 6. In vivo treatment with cetuximab decreased tumor growth/weight and intra-tumoral urokinase-type plasminogen activator (uPA) expression. A, Tumor growth of subcutaneously injected CASKI cells $\left(1 \times 10^{7}\right)$ into Balb/c nude mice. The arrows indicate the time points in which PBS or $1 \mathrm{mg}$ cetuximab were administered intraperitoneally in a final volume of $200 \mu \mathrm{L}$ per animal. After euthanasia of the animals, tumors were excised, weighed (B), prepared for RNA extraction, and quantitative real-time PCR was performed for uPA (C) and thrombomodulin (TM) (D). Two-sample Student's $t$-test was used for statistical analysis comparing control group $(n=8)$ vs cetuximab group $(n=6)$.

A meta-analysis published in 2002 , with data from 8,377 breast cancer patients, showed that increased uPA levels correlated with worse disease-free and overall survival (28). Serum uPA levels in 252 breast cancer patients were positively correlated with worse progression-free and overall survival, as well as associated with an increase in plasma HER2 levels, a receptor of the EGFR family (29). In 2014, however, another study showed that plasma levels of uPA did not correlate with lymph node metastasis status, also in human breast cancer (30). In colorectal cancer, uPA levels in plasma or primary site vs normal mucosa did not correlate with alterations in patient survival (31). In cervical cancer, Sugimura et al. showed that uPA staining in primary tumor biopsies correlated positively with lymph node metastasis status (32). Another group in 2002, however, did not observe any prognostic impact of intra-tumoral uPA, also among cervical cancer patients (33).

It has been shown that the UPA receptor, UPAR, can transactivate EGFR (19) and that both UPA and UPAR participate in the resistance mechanisms towards antiEGFR treatment in glioblastoma $(21,22)$. One hypothesis that arises in light of these results is that, in cervical cancer, there may be a positive feedback loop, in which EGFR positively regulates UPA expression, and that its receptor, UPAR, may favor EGFR transactivation, as has been shown in glioblastoma (19). Furthermore, the silencing of UPA and UPAR in a pancreatic cancer model reduces in vivo tumor growth and angiogenesis (34). A clinical trial has been published using an uPA inhibitor called WX-671 in locally advanced pancreatic cancer, showing no notable difference between groups treated with chemotherapy alone or in combination with UPA inhibition (35). Another clinical trial using a competitive inhibitor of the binding between UPA and UPAR, called A6, showed minimal beneficial effects on patients with gynecological tumors such as the ovary, fallopian tube, and peritoneum (36). Perhaps finding signaling partners for either EGFR or UPA could be useful in optimizing therapeutic efficiency for these targets. 
In the present work, we showed that EGFR, uPA, and TM levels of human cervical tumors correlated with worse overall patient survival and that UPA and TM were positively regulated by EGFR. Furthermore, uPA expression can have a direct impact on cervical cancer cell function, specifically EGFR-dependent cell morphology modifications and EGFR-independent cell migration. To the best of our knowledge, we are the first to show this interplay between EGFR signaling and components of the fibrinolytic system in cervical cancer. Therefore, we propose UPA as a potentially novel candidate to be studied in combination with EGFR in cervical cancer, either as a therapeutic target or as a biomarker for EGFR signaling and patient prognosis.

\section{Supplementary Material}

Click here to view [pdf].

\section{References}

1. WHO. Cervical cancer.<https://www.who.int/cancer/prevention/ diagnosis-screening/cervical-cancer/en/ $>$. Accessed on March 3, 2020.

2. Instituto Nacional de Câncer (BR) Coordenação de Prevenção e Vigilância. Estimativa 2020: incidência de câncer no Brasil. Rio de Janeiro: INCA; 2019.

3. Subramanya D, Grivas PD. HPV and cervical cancer: updates on an established relationship. Postgrad Med 2008; 120: 7-13, doi: 10.3810/pgm.2008.11.1928.

4. Wang Z. ErbB receptors and cancer. Methods Mol Biol 2017; 1652: 3-35, doi: 10.1007/978-1-4939-7219-7_1.

5. Sigismund $S$, Avanzato D, Lanzetti L. Emerging functions of the EGFR in cancer. Mol Oncol 2018; 12: 3-20, doi: 10.1002/1878-0261.12155

6. Tian WJ, Huang ML, Qin QF, Chen Q, Fang K, Wang PL. Prognostic impact of epidermal growth factor receptor overexpression in patients with cervical cancer: a metaanalysis. PLoS One 2016; 11: e0158787, doi: 10.1371/ journal.pone. 0158787 .

7. Maufort JP, Shai A, Pitot HC, Lambert PF. A role for HPV16 E5 in cervical carcinogenesis. Cancer Res 2010; 70: 29242931, doi: 10.1158/0008-5472.CAN-09-3436.

8. Manzo-Merino J, Contreras-Paredes A, Vázquez-Ulloa E, Rocha-Zavaleta L, Fuentes-Gonzalez AM, Lizano M. The role of signaling pathways in cervical cancer and molecular therapeutic targets. Arch Med Res 2014; 45: 525-539, doi: 10.1016/j.arcmed.2014.10.008.

9. Hertlein L, Lenhard M, Kirschenhofer A, Kahlert S, Mayr D, Burges $A$, et al. Cetuximab monotherapy in advanced cervical cancer: a retrospective study with five patients. Arch Gynecol Obstet 2011; 283: 109-113, doi: 10.1007/ s00404-010-1389-1.

10. Kurtz JE, Hardy-Bessard AC, Deslandres M, Lavau-Denes $\mathrm{S}$, Largillier R, Roemer-Becuwe $\mathrm{C}$, et al. Cetuximab, topotecan and cisplatin for the treatment of advanced

\section{Acknowledgments}

We would like to sincerely thank PhD student Clarissa França Dias Carneiro for assistance in formatting figures and quality of reporting, Prof. Dr. Luciana Serrão and Prof. Dr. Jerson Lima for allowing the use of their facilities and equipment, and Ms. Rosangela Araujo and the team of animal care at the National Center of Structural Biology and Bioimaging (CENABIO) for technical assistance. This work was supported by the National Council for Scientific and Technological Development (CNPq, grant number 309946/2018-2), the Coordination for the Improvement of Higher Education Personnel (CAPES, grant number 23038. 008921/2019-15), the Carlos Chagas Filho Foundation for Research Support of the State of Rio de Janeiro (FAPERJ, grant number E-26/202.871/2018), and The Brazilian Cancer Foundation. cervical cancer: a phase II GINECO trial. Gynecol Oncol 2009; 113: 16-20, doi: 10.1016/j.ygyno.2008.12.040.

11. Nogueira-Rodrigues A, Moralez G, Grazziotin R, Carmo CC, Small IA, Alves FV, et al. Phase 2 trial of erlotinib combined with cisplatin and radiotherapy in patients with locally advanced cervical cancer. Cancer 2014; 120: 1187-1193, doi: 10.1002/cncr.28471.

12. Malone JM, Wangensteen SL, Moore WS, Keown K. The fibrinolytic system. A key to tumor metastasis? Ann Surg 1979; 190: 342-349, doi: 10.1097/00000658-197909000-00009.

13. Heissig B, Eiamboonsert S, Salama Y, Shimazu H, Dhahri $\mathrm{D}$, Munakata $\mathrm{S}$, et al. Cancer therapy targeting the fibrinoIytic system. Adv Drug Deliv Rev 2016; 99: 172-179, doi: 10.1016/j.addr.2015.11.010.

14. Lin $\mathrm{H}, \mathrm{Xu} \mathrm{L}, \mathrm{Yu} \mathrm{S}$, Hong $\mathrm{W}$, Huang M, Xu P. Therapeutics targeting the fibrinolytic system. Exp Mol Med 2020; 52: 367-379, doi: 10.1038/s12276-020-0397-x.

15. Tang $L$, Han $X$. The urokinase plasminogen activator system in breast cancer invasion and metastasis. Biomed Pharmacother 2013; 67: 179-182, doi: 10.1016/j.biopha.2012.10.003.

16. Didiasova M, Wujak L, Wygrecka M, Zakrzewicz D. From plasminogen to plasmin: role of plasminogen receptors in human cancer. Int J Mol Sci 2014; 15: 21229-21252, doi: 10.3390/ijms151121229.

17. Cheng TL, Chen PK, Huang WK, Kuo CH, Cho CF, Wang KC, et al. Plasminogen/thrombomodulin signaling enhances VEGF expression to promote cutaneous wound healing. $\mathrm{J} \mathrm{Mol} \mathrm{Med}$ (Berl) 2018; 96: 1333-1344, doi: 10.1007/s00109-018-1702-1.

18. Mahmood N, Mihalcioiu C, Rabbani SA. nFront multifaceted role of the urokinase-type plasminogen activator (UPA) and its receptor (UPAR): diagnostic, prognostic, and therapeutic applications. Front Oncol 2018; 8: 24, doi: 10.3389/fonc. 2018.00024.

19. Jo M, Thomas KS, O'Donnell DM, Gonias SL. Epidermal growth factor receptor-dependent and -independent 
cell-signaling pathways originating from the urokinase receptor. J Biol Chem 2003; 278: 1642-1646, doi: 10.10 74/jbc.M210877200.

20. Amos S, Redpath GT, Dipierro CG, Carpenter JE, Hussaini IM. Epidermal growth factor receptor-mediated regulation of urokinase plasminogen activator expression and glioblastoma invasion via C-SRC/MAPK/AP-1 signaling pathways. J Neuropathol Exp Neurol 2010; 69: 582-592, doi: 10.1097/ NEN.0b013e3181e008fe.

21. Hu J, Muller KA, Furnari FB, Cavenee WK, VandenBerg SR, Gonias SL. Neutralizing the EGF receptor in glioblastoma cells stimulates cell migration by activating UPARinitiated cell signaling. Oncogene 2015; 34: 4078-4088, doi: 10.1038/onc.2014.336.

22. Wykosky J, Hu J, Gomez GG, Taylor T, Villa GR, Pizzo D, et al. A urokinase receptor-Bim signaling axis emerges during EGFR inhibitor resistance in mutant EGFR glioblastoma. Cancer Res 2015; 75: 394-404, doi: 10.1158/00085472.CAN-14-2004.

23. Gao J, Aksoy BA, Dogrusoz U, Dresdner G, Gross B, Sumer $\mathrm{SO}$, et al. Integrative analysis of complex cancer genomics and clinical profiles using the cBioPortal. Sci Signal 2013; 6: pl1, doi: 10.1126/scisignal.2004088.

24. Cerami E, Gao J, Dogrusoz U, Gross BE, Sumer SO, Aksoy BA, et al. The cBio cancer genomics portal: an open platform for exploring multidimensional cancer genomics data. Cancer Discov 2012; 2: 401-404, doi: 10.1158/21598290.CD-12-0095.

25. Tilli TM, Castro CS, Tuszynski JA, Carels N. A strategy to identify housekeeping genes suitable for analysis in breast cancer diseases. BMC Genomics 2016; 17: 639, doi: 10.1186/s12864-016-2946-1.

26. de Almeida VH, Guimarães IDS, Almendra LR, Rondon AMR, Tilli TM, de Melo AC, et al. Positive crosstalk between EGFR and the TF-PAR2 pathway mediates resistance to cisplatin and poor survival in cervical cancer. Oncotarget 2018; 9: 30594-30609, doi: 10.18632/oncotarget.25748.

27. Chong CR, Jänne PA. The quest to overcome resistance to EGFR-targeted therapies in cancer. Nat Med 2013; 19: 1389-1400, doi: 10.1038/nm.3388.

28. Look MP, van Putten WL, Duffy MJ, Harbeck N, Christensen IJ, Thomssen C, et al. Pooled analysis of prognostic impact of urokinase-type plasminogen activator and its inhibitor
PAI-1 in 8377 breast cancer patients. J Natl Cancer Inst 2002; 94: 116-128, doi: 10.1093/jnci/94.2.116.

29. Banys-Paluchowski M, Witzel I, Aktas B, Fasching PA, Hartkopf A, Janni $W$, et al. The prognostic relevance of urokinase-type plasminogen activator (UPA) in the blood of patients with metastatic breast cancer. Sci Rep 2019; 9: 2318, doi: 10.1038/s41598-018-37259-2.

30. Harms W, Malter W, Krämer S, Drebber U, Drzezga A, Schmidt M. Clinical significance of urokinase-type plasminogen activator (UPA) and its type-1 inhibitor (PAl-1) for metastatic sentinel lymph node involvement in breast cancer. Anticancer Res 2014; 34: 4457-4462.

31. Langenskiöld M, Holmdahl L, Angenete E, Falk P, Nordgren $S$, Ivarsson ML. Differential prognostic impact of UPA and PAl-1 in colon and rectal cancer. Tumour Biol 2009; 30: 210-220, doi: 10.1159/000239796.

32. Sugimura M, Kobayashi H, Kanayama N, Terao T. Clinical significance of urokinase-type plasminogen activator (UPA) in invasive cervical cancer of the uterus. Gynecol Oncol 1992; 46: 330-336, doi: 10.1016/0090-8258(92)90227-A.

33. Horn LC, Pippig S, Raptis G, Fischer U, Köhler U, Hentschel $B$, et al. Clinical relevance of urokinase-type plasminogen activator and its inhibitor type 1 (PAl-1) in squamous cell carcinoma of the uterine cervix. Aust N Z J Obstet Gynaecol 2002; 42: 383-386, doi: 10.1111/j.0004-8666.2002.00385.x.

34. Gorantla B, Asuthkar S, Rao JS, Patel J, Gondi CS. Suppression of the UPAR-uPA system retards angiogenesis, invasion, and in vivo tumor development in pancreatic cancer cells. Mol Cancer Res 2011; 9: 377-389, doi: 10.1158/1541-7786.MCR-10-0452.

35. Heinemann V, Ebert MP, Laubender RP, Bevan P, Mala C, Boeck S. Phase II randomised proof-of-concept study of the urokinase inhibitor upamostat (WX-671) in combination with gemcitabine compared with gemcitabine alone in patients with non-resectable, locally advanced pancreatic cancer.

Br J Cancer 2013; 108: 766-770, doi: 10.1038/bjc.2013.62.

36. Gold MA, Brady WE, Lankes HA, Rose PG, Kelley JL, De Geest K, et al. A phase II study of a urokinase-derived peptide (A6) in the treatment of persistent or recurrent epithelial ovarian, fallopian tube, or primary peritoneal carcinoma: a Gynecologic Oncology Group study. Gynecol Oncol 2012; 125: 635-639, doi: 10.1016/j.ygyno.2012.03.023. 